\title{
O DESENVOLVIMENTO SUSTENTÁVEL EM UNIDADE DE CONSERVAÇÃO: a "naturalização" do social
}

\section{Cristina Teixeira}

\section{Introdução}

O desenvolvimento sustentável foi institucionalizado como solução para a resolução de "problemas" causados pela ocupação humana em unidades de conservação (UC), um dos aspectos polêmicos na administração de áreas protegidas.

A proposta de delimitação de áreas protegidas sem ocupação humana, presente na criação dos primeiros parques nacionais, foi gradativamente modificada pela inexorável presença da sociedade no espaço que se pretendia proteger. A aceitação da ocupação humana em áreas protegidas ocorreu via a regulamentação e o controle do uso dos recursos naturais. No entanto, a ineficiência dessa solução manteve sem resposta uma questão essencial para as atuais unidades de con-

Artigo recebido em novembro/2004 Aprovado em agosto/2005 servação, isto é, o problema de como executar a conservação da biodiversidade, objetivo principal da conservação, mantendo a ocupação humana em seu interior. Atualmente, a resposta dos diversos agentes envolvidos com a gestão de áreas protegidas refere-se à promoção do desenvolvimento sustentável. Isto pode ser observado no Sistema Nacional de Unidades de Conservação (SNUC), instituído em 2000.

O SNUC é o resultado de uma década de debates e enfrentamento de interesses que envolveram ambientalistas, cientistas, organizações não-governamentais (ONGs), representantes de populações tradicionais, organizações ambientalistas internacionais, organizações privadas, entre outros. Durante este período, a ocupação humana em unidades de conservação foi bastante discutida. A saída encontrada seguiu diretrizes internacionais sobre unidades de conservação, adotando a proposição de uso sustentável dos recursos naturais (Lei 9.985/2000, Art. 2. II). 
Partindo da idéia de uso sustentável, o SNUC estabelece como um de seus objetivos "promover o desenvolvimento sustentável a partir dos recursos naturais" (Idem, Art. 4º IV). Assim, incorpora a noção de desenvolvimento sustentável da II Conferência das Nações Unidas sobre o Meio Ambiente e Desenvolvimento (UNCED), conhecida como Rio-92.

Mas, antes mesmo do SNUC, a idéia de uso sustentável dos recursos naturais já se manifestava em certas categorias de unidade de conservação no Brasil, desde os anos de 1980. Além disso, principalmente após a Rio-92, uma série de projetos de conservação e desenvolvimento passaram a ser executados em unidades de conservação na esteira do desenvolvimento sustentável, envolvendo ONGs ambientalistas.

Embora tenha sido adotada como uma saída consensual para solucionar problemas relativos à ocupação humana em unidades de conservação, a utilização generalizada da noção de desenvolvimento sustentável requer cautela. Instituída como solução para o dilema entre desenvolvimento socioeconômico e conservação ambiental, apresenta problemas relacionados ao próprio conceito de sustentabilidade e às dificuldades da sua execução (ecológica, social e econômica) no sistema capitalista.

A análise de propostas de desenvolvimento visando à conservação em unidades de conservação pode contribuir para a identificação de elementos que questionem a funcionalidade, as contradições e os limites do desenvolvimento sustentável, envolvendo, em última instância, a reflexão sobre a relação entre a sociedade e o ambiente. Este artigo apresenta o caso da Área de Proteção Ambiental (APA) de Guaraqueçaba, localizada no litoral norte do Paraná, onde o uso e o desenvolvimento sustentáveis foram propostos por sua administração (órgãos governamentais ambientais em parceira com ONGs ambientalistas) no sentido de solucionar os conflitos entre a conservação e o uso dos recursos naturais realizado pela pequena agricultura local. Em Guaraqueçaba, a solução encontrada fundamentou-se numa perspectiva de articulação entre a sociedade e o ambiente, caracterizada pela "naturalização" da sociedade.

\section{A ocupação humana em UC: da exclusão ao desenvolvimento sustentável}

Os objetivos estéticos e científicos que justificaram a criação das primeiras áreas protegidas os parques nacionais, a partir do final do século XIX - eram considerados incompatíveis com a ocupação humana em seus limites (Brito, 2000).

A partir dos anos de 1970, essa perspectiva foi sendo substituída pela possibilidade de manutenção da ocupação humana em áreas protegidas mediante o controle do uso dos recursos naturais. Isso pode ser observado na mudança das diretrizes de organismos internacionais, particularmente da União Internacional pela Conservação da Natureza (UICN), referência internacional das diretrizes das áreas protegidas (Idem). Na década seguinte, a UICN condicionou a ocupação ao uso sustentável dos recursos naturais, garantindo assim a prioridade da conservação (Diegues, 2000).

A Unesco elaborou, em 1971, o programa Man and Biosphere (MAB), cujo objetivo era encontrar uma relação de equilíbrio entre desenvolvimento econômico e conservação ambiental. Este programa definiu, em 1976, o conceito de Reserva da Biosfera como forma de alcançar a "otimização da relação homem-natureza”. Tais reservas seriam "exemplos de gestão harmoniosa de diferentes culturas [...] sítios de experimentação do desenvolvimento sustentado e [...] centros de monitoramento, pesquisa e educação ambiental" (Brito, 2000, p. 29). Por meio do zoneamento, ${ }^{1}$ seriam preservadas áreas sem ocupação humana, cercadas por "zonas-tampão", que poderiam ser habitadas.

Essas propostas respondiam aos efeitos perversos da exclusão de populações que viviam nos parques, uma vez que o seu deslocamento e as restrições de uso de recursos naturais em áreas protegidas demonstraram ser uma ameaça à reprodução de populações consideradas tradicionais, geralmente já castigadas pela pobreza (Idem). Além disso, observou-se que nem sempre as práticas produtivas dessas populações eram incompatíveis com os objetivos da conservação (Diegues, 2000).

Paralelamente, os debates relativos às causas sociais da crise ambiental e à contradição entre 
crescimento econômico e conservação ambiental desenvolviam-se em conferências internacionais, cujos temas diziam respeito aos limites do crescimento econômico, aos impactos da pobreza na degradação dos recursos naturais e às possibilidades do ecodesenvolvimento (Nobre, 2002).

O Brasil incorporou as reflexões sobre ocupação humana em UC, seguindo o programa Man and Biosphere, a partir dos anos de 1980. Diante da cobrança de organismos internacionais para uma postura mais efetiva do país voltada à conservação ambiental, o Brasil elaborou, pois, sua primeira proposta de criação de um Sistema Nacional de Unidades de Conservação, com categorias nas quais o uso sustentável era permitido (Brito, 2000).

Nesse mesmo período, a proteção ambiental passou a ser enfocada a partir do que denominamos ecologismo social ou socioambientalismo, ou seja, diversos movimentos sociais começaram a considerar a questão ambiental uma de suas causas (Diegues, 1998; Leis e Viola, 1996). Assim, desencadearam-se propostas para o extrativismo e a agricultura - atividades que permitiam a reprodução de populações tradicionais -, mantendo seu acesso aos recursos naturais e sua participação no planejamento e na gestão das unidades de conservação. A Reserva Extrativista (Resex), criada em 1990, constituiu-se dentro desse contexto e, atualmente, é a principal categoria utilizada para conservação em áreas ocupadas por populações tradicionais.

A constatação da compatibilidade entre o uso dos recursos naturais e a conservação ambiental foi reafirmada em estudos sobre essas populações realizados pelo Núcleo de Pesquisas sobre População Humana em Áreas Úmidas Brasileiras (NUPAUB) da Universidade de São Paulo a partir de 1987. Esses estudos foram importantes não só para analisar as especificidades da relação entre sociedades tradicionais e meio ambiente, como também para identificar os problemas socioeconômicos decorrentes da delimitação de áreas protegidas. Dentre eles, destacam-se os conflitos entre população local e órgãos de conservação, resultantes das restrições às práticas tradicionais de uso dos recursos naturais necessários à reprodução socioeconômica dessas populações.

$\mathrm{Na}$ década de 1990, o desenvolvimento sustentável passou a ser utilizado como referência para resolver problemas e conflitos relativos à ocupação humana em unidades de conservação. Na conferência Rio-92, oficializou-se a noção de desenvolvimento sustentável, definida no Relatório Brundtland, em 1987, como paradigma para o desenvolvimento socioeconômico aliado à conservação dos recursos naturais. O Estado brasileiro e outros países signatários da Agenda $21 \mathrm{Global}^{2}$ assumiram o compromisso de adotá-la como orientação para suas políticas de desenvolvimento.

Ao mesmo tempo, sob a ótica da promoção do desenvolvimento sustentável e seguindo ainda as diretrizes internacionais, um número significativo de ONGs ambientalistas em parceria ou não com órgãos governamentais envolveu-se na questão relativa ao desenvolvimento socioeconômico. Essas instituições propuseram e/ou realizaram ações voltadas para o aumento de renda ou a melhoria da qualidade de vida de populações em unidades de conservação, cujo uso dos recursos naturais era considerado incompatível com a conservação (Teixeira, 2004).

O atual SNUC incorporou o desenvolvimento sustentável, e as áreas em questão passaram a ser denominadas Unidades de Uso Sustentável, ${ }^{3}$ das quais fazem parte a Resex e a APA. Essas unidades objetivam "compatibilizar a conservação da natureza com o uso sustentável de parcela dos seus recursos naturais" (Art. $7^{\circ} \ 2^{\circ}$ ), mediante plano de manejo elaborado por uma equipe técnico-científica.

Posteriormente à proteção da diversidade biológica, dos recursos genéticos, das espécies ameaçadas e da diversidade dos ecossistemas, o SNUC estabelece ainda outras regulamentações que procuram compatibilizar a conservação à ocupação humana - proteção de recursos naturais necessários à subsistência de populações tradicionais, promovendo-as social e economicamente; desenvolvimento e adaptação de métodos e técnicas de uso sustentável dos recursos naturais; garantia da participação na criação; implantação e gestão das unidades de conservação como, por exemplo, a formação de conselho consultivo ou deliberativo nas Unidades de Conservação de Uso Sustentável; divulgação de informações à população local e a outras partes interessadas; incentivo à criação e à administração das unidades por parte das populações locais na perspectiva de "COgestão", entre outras medidas (Lei nº 9.985/2000). 
A adoção das determinações do SNUC ocorre sob a dinâmica de gestão de unidades de conservação já existentes no país. Algumas delas sequer elaboraram seus zoneamentos e planos de gestão; outras, em menor número, além de já se utilizarem desses instrumentos, contam também com projetos de ação de desenvolvimento e de conservação em andamento. Este é o caso da APA de Guaraqueçaba, administrada pelo órgão governamental ambiental federal, responsável pela criação e gestão de unidades de conservação, do Instituto Brasileiro do Meio Ambiente e dos Recursos Naturais Renováveis (Ibama) em parceria com uma ONG ambientalista paranaense, à qual se atribui uma influência significativa sobre sua gestão.

A partir de 2000, a referida gestão incorporou a noção de desenvolvimento sustentável, não só por determinação do SNUC, mas outras condições objetivas exigiram a adoção de projetos de desenvolvimento sustentável para a pequena agricultura.

Antes de analisar o caso da APA de Guaraqueçaba, algumas observações sobre a noção de desenvolvimento sustentável serão discutidas de maneira breve para que se reflita tanto sobre as possibilidades de realização, como sobre a própria noção de desenvolvimento sustentável.

\section{Os problemas advindos da noção de desenvolvimento sustentável}

A noção de desenvolvimento sustentável utilizada para subsidiar ações conservacionistas originou-se de uma discussão mais geral relacionada ao confronto entre a necessidade de crescimento econômico e a necessidade de conservação dos recursos naturais. Ademais, foi legitimada por estabelecer um pretenso consenso entre essas duas dimensões, originalmente consideradas opostas (Castells, 2000; Foladori e Tommasino, 2000; Nobre, 2002). Tal consenso tem como princípio geral atender às necessidades do presente, sem comprometer as possibilidades de as gerações futuras sanarem suas próprias necessidades.

Um primeiro grupo de críticas ao desenvolvimento sustentável concentra suas discussões em torno de quais seriam a funcionalidade e os limites desse desenvolvimento. Não se pode afirmar, como já argumentaram alguns setores do movimento ambiental (Castells, 2000), que esse tipo de desenvolvimento se oponha à "lógica" do modelo de crescimento econômico capitalista, uma vez que ele não vai contra as causas estruturais da insustentabilidade, tornando-se, pois, funcional ao sistema (Becker, 1999; Leff, 2000; Leis, 1999; Lelé, 1991; Foladori, 1999; Middleton e O'Keefe, 2001).

Antes mesmo da Rio-92, Lelé (1991) afirmava que os "desenvolvimentistas" e o movimento ambientalista deixaram de lado suas diferenças no sentido de convergirem ambos para uma proposta de desenvolvimento sustentável. Assim, passaram a enfrentar juntos os problemas relativos aos limites ambientais do crescimento econômico e as questões sociais, basicamente pobreza e desigualdade. Uniram-se sob o imperativo de uma possibilidade, qual seja, a realização da sustentabilidade ambiental, mantendo a continuidade do sistema produtivo e das relações sociais que o sustentam.

Segundo Leis (1999, p. 159), o conceito de desenvolvimento sustentável faria parte de um processo de "adoção oportunista e instrumental [...]", por parte dos estados e das empresas, de novos valores trazidos pelo ambientalismo, com o objetivo de garantir a continuidade do sistema produtivo. Assim, a racionalidade econômica dominante diluiu o potencial transformador das origens do movimento ambiental, confundindo e dispersando suas ações (Leff, 2000).

O "capitalismo verde" tem como tese a funcionalidade desse tipo de desenvolvimento, pois apesar da sustentabilidade "seriam preservados não apenas os recursos naturais, mas também e acima de tudo, infelizmente, as relações de produção existentes" (Vargas, 1999, p. 230). Para Foladori (1999), tais relações estabelecem os limites do desenvolvimento sustentável.

As causas sociais da insustentabilidade passaram a ser abordadas, e a sustentabilidade social foi incluída como parte imprescindível do desenvolvimento sustentável (Lelé, 1991). Porém, isso não significou o reconhecimento das relações sociais como responsáveis pela insustentabilidade ecológica. Segundo Foladori e Tommasino (2000), a pobreza foi considerada uma de suas causas, o que acarretaria a necessidade de se agir sobre a pobreza, ou seja, encontrar a sustentabilidade social para promover a sustentabilidade ecológi- 
ca. A solução para o desenvolvimento sustentável, nessa perspectiva, estava centrada no conhecimento científico e no desenvolvimento de técnicas de produção adequadas à conservação dos recursos naturais. Os métodos de produção deveriam ser menos agressivos ao meio natural e poderiam levar à melhoria da qualidade de vida, ou ao desenvolvimento, minimizando os impactos antrópicos sobre o meio ambiente. Esta perspectiva foi chamada de sustentabilidade limitada:

[...] restringindo seu papel de ponte para a análise da sustentabilidade ecológica [...] o que interessa são as relações técnicas entre os pobres e o uso dos recursos naturais. As relações sociais, que se referem a como determinadas relações entre os seres humanos geram pobreza, desemprego, fome etc., não estão em discussão, senão somente suas consequiências técnicas na contaminação e depredação do meio (Idem, pp. 46-47).

Nesse primeiro grupo de críticas encontram-se, ainda, análises que se referem à operacionalização do desenvolvimento sustentável. Para isso, a escala da "localidade" foi a saída encontrada, uma vez que as escalas de "humanidade", "planeta terra" e "economia global" são aparentemente inoperantes, ou operantes somente no nível Estados Nacionais. Becker considera que a sustentabilidade configura uma nova racionalidade do sistema capitalista e reconfigura o desenvolvimento a partir da localidade ou da região. Ela seria, segundo este autor, um dos

[...] instrumentos pós-modernos que, ao mesmo tempo em que viabilizam a dominação em escala mundial, abrem a possibilidade, embora dentro de limites muito objetivos e concretos, e muito mais por necessidade do próprio sistema capitalista, para as histórias locais, as tradições do lugar, enfim, para os desejos, necessidades e fantasias fragmentadas (1999, p. 64).

Ao analisarem a ação de ONGs em projetos "locais" na Europa, Middleton e O'Keefe (2001) afirmaram que há dois equívocos na atuação baseada na localidade. O primeiro refere-se aos limites do "empoderamento" (empowerment) local, já que os mecanismos de opressão estão nas relações sociais, cujas causas não são alcançadas. O segundo diz respeito aos limites da atuação, isto é, as ações res- tritas à esfera local só poderão resolver problemas circunscritos a uma determinada área, mas as causas da insustentabilidade estão localizadas na escala da macroeconomia e da macropolítica.

À localidade alia-se a participação social. Segundo Lelé (1991), ao legitimar o conceito de desenvolvimento sustentável, questões como justiça e eqüidade sociais, que estavam presentes no conceito de ecodesenvolvimento, foram abandonadas e substituídas pela participação social, mais especificamente pela participação local. Partindo da sustentabilidade como referencial indiscutível, e da solução técnica como saída para a recuperação e a utilização dos recursos naturais (Foladori e Tommasino, 2001), observa-se que a participação local ficaria restrita a decidir sobre rol de possibilidades técnicas possíveis para promover a sustentabilidade ecológica. O saber local, por exemplo, é visto como possibilidade de obtenção de mais informações sobre como lidar com os recursos naturais, contribuindo para a elaboração de soluções técnicas no uso dos recursos naturais.

O segundo grupo de críticas concentra-se na apropriação do conceito de sustentabilidade ecológica para adjetivar o desenvolvimento socioeconômico, ou ainda, para se referir à sustentabilidade social ou econômica. A noção de sustentabilidade originada na ecologia para analisar os sistemas naturais (sustentabilidade ecológica), deve ser deslocada para a análise das organizações sociais (sustentabilidade social). Deve-se estabelecer uma contraposição à tendência encontrada nas noções de sustentabilidade que utilizam como referência "equilíbrio" e "estabilidade":

\footnotetext{
A noção de sustentabilidade ou de durabilidade se origina de teorizações e práticas ecológicas que tentam analisar a evolução temporal de recursos naturais, tomando por base a sua persistência, manutenção ou capacidade de retorno a um presumido estado de equilíbrio, após algum tipo de perturbação. A noção de equilíbrio é tema polêmico e controverso, mesmo no domínio ecológico, já que os sistemas naturais, incluídos neles os chamados recursos renováveis, estão sujeitos a elevada variabilidade, expressa em distintas escalas temporais e espaciais (Raynaut, Lana e Zanoni, 2000, p. 74).
}

Segundo Raynaut (1997, p. 370), a utilização dessa noção pode levar à interpretação de uma 
história que não comporta outro movimento que não "a reprodução incomensurável de um equilíbrio impossível" da natureza e da sociedade. Esta história deve ser entendida como o resultado de uma relação dialética entre reprodução e mudança, uma vez que cada sistema comporta a reprodução e, ao mesmo tempo, se transforma, seja em função de suas próprias contradições, seja em função de fatores externos.

Há uma relação de interdependência e autonomia entre esses dois sistemas. Ainda que qualquer organização social exija materialidade para existir (corpo, terra, água etc.), o sentido elaborado socialmente, referente às ações humanas sobre o meio natural, torna-se autônomo em relação às determinações do meio físico-químico e biológico, podendo ser transmitido para outras gerações e outras sociedades diferentes daquelas (Zanoni e Raynaut, 1994).

Mesmo no campo das ciências biológicas a perspectiva do equilíbrio estável e preditivo foi substituída por outras que constatam a existência de equilíbrio dinâmico nos sistemas biológicos. Segundo Miranda (2003), novos conceitos têm sido aceitos para a análise desses sistemas, como, por exemplo, os conceitos de resiliência e de co-evolução. O primeiro considera mais de uma possibilidade de equilíbrio e a extinção do sistema; o segundo considera a interatividade de ajustamentos das espécies em um determinado sistema, em que as espécies evoluem conjuntamente, e a evolução de cada uma é interdependente da evolução da outra.

Esses dois grupos de crítica levantam, ainda, a discussão sobre o sujeito da sustentabilidade. Geralmente, a humanidade e o meio ambiente são definidos como os beneficiários do desenvolvimento sustentável. Porém, a humanidade não pode ser considerada "em bloco", uma vez que só existe na forma de organização social. Nesta, desenvolvem-se as relações sociais que interferem nas relações que os grupos sociais estabelecem de maneiras diversas com o meio natural, a partir de interesses e possibilidades específicos a cada um deles (Foladori, 1999; Raynaut, 1994). Logo, reduzir o sujeito da sustentabilidade à humanidade é retirar da sociedade suas características estruturais por meio das quais devemos pensar sua relação com o meio natural. Isso fundamentaria, em última instância, qualquer proposta de desenvolvimento integrado à sustentabilidade ecológica.

\section{A sustentabilidade na APA de Guaraqueçaba}

Propostas de desenvolvimento para população em unidades de conservação só se realizam a partir de um objetivo principal, qual seja, a conservação da biodiversidade. Em Guaraqueçaba isto não foi diferente.

Há alguns estudos locais que enfocaram a questão da sustentabilidade a partir da idéia dos limites do desenvolvimento sustentável. Particularmente foram enfatizados a insustentabilidade de sistemas produtivos e a sustentabilidade, ponte para atingir a conservação (Rodrigues, 2002; Tommasino, 2002).

Neste artigo, pretendo discutir uma outra dimensão do desenvolvimento sustentável, que interessa particularmente às ciências sociais: a "naturalização" da sociedade nas propostas e nas ações para a promoção da sustentabilidade em uma unidade de conservação que se fundamentam em soluções técnicas. Isto será analisado a partir do processo de proteção ambiental na APA de Guaraqueçaba, a partir dos anos de 1990, quando, então, o uso e o desenvolvimento sustentáveis tornaram-se referência das propostas de desenvolvimento da agricultura local.

\section{A proteção ambiental na APA de Guaraqueçaba}

Distante $167 \mathrm{~km}$ de Curitiba, a APA de Guaraqueçaba possui uma extensão de $3.143 \mathrm{~km}$ (Ipardes, 2001), dos quais $81,83 \%$ é ocupado pelo município de Guaraqueçaba, todo ele incluído na APA. ${ }^{4}$ Possui 8.288 habitantes, sendo que a maior parte $-68,85 \%-$ vive na zona rural. A população distribui-se em vinte localidades ao longo dos vales dos rios. A pequena agricultura corresponde à maior parte das atividades produtivas locais, relativas à produção de banana e mandioca (Rodrigues, 2002).

Para além da importância dada às suas características ambientais, Guaraqueçaba é considerada um importante patrimônio cultural, representado por pescadores e agricultores que guardam remanescentes da cultura "tradicional" caiçara, inclusive nas práticas de uso dos recursos naturais (Ipardes, 2001).

A proteção ambiental na região de Guaraqueçaba iniciou-se nos anos de 1980, com a cria- 
ção de unidades de conservação e com a chegada de órgãos governamentais para execução das ações de controle de uso dos recursos naturais. As características ambientais da região aliadas ao desenvolvimento do movimento ambiental no Brasil e no mundo atraíram a atenção de organismos internacionais, dos governos estadual e federal e de ONGs ambientalistas. O meio natural, considerado um ambiente conservado, encontrava-se em vias de degradação, por causa da exploração da madeira, do palmito e da pesca (Teixeira, 2004).

A responsabilidade desse quadro foi atribuída à dinâmica social que ora se desencadeava na região, decorrente da nova ocupação iniciada nas décadas anteriores. Segundo Miguel (1997), no continente, os neolatifundiários - grupos de empresas madeireiras e grupos industriais e comerciais - instalaram grandes propriedades destinadas à exploração dos recursos naturais ou à especulação, em geral realizada mediante a grilagem de terras, a partir da década de 1960. Além da intensificação da exploração de recursos naturais (madeira e palmito), agricultores e pescadores foram expropriados, o que acentuou a pobreza da população local. Paralelamente, a superexploração dos recursos pesqueiros por meio da pesca predatória e ilegal realizada no estuário acarretou a redução dos recursos que abasteciam as comunidades de pescadores (Fundação SOS pró-Mata Atlântica, 1986).

A proteção ambiental em Guaraqueçaba instituiu a conservação do meio natural em um espaço caracterizado por sérios problemas econômi$\cos$ e sociais $^{5}$ e insatisfatoriamente atingido por políticas e programas de desenvolvimento estaduais e federais (Miguel, 1997). Ela se tornou mais um obstáculo para a maior parte da sociedade local, na medida em que restringiu o uso dos recursos naturais necessários à produção e à complementação das atividades produtivas da população (Miguel, 1997; Miguel e Zanoni, 1998).

A história desse processo teve períodos distintos, nos quais se apresentaram diferentes agentes e concepções sobre a proteção ambiental e sobre o desenvolvimento da sociedade local (Teixeira, 2004).

No período que corresponde à década de 1980, a proteção caracterizou-se por ações no sentido de implantar unidades de conservação na região (construção da sede, zoneamento, entre outros). O órgão ambiental federal (Sema, Ibama), responsável pela criação dessas unidades, possuía uma atuação bastante reduzida na região. O controle de uso dos recursos naturais (licenciamento e fiscalização) ficou basicamente a cargo do órgão estadual do Paraná com atribuições ambientais. Este órgão atuou no sentido de aplicar a legislação já existente, como o Código Florestal e a Lei de Uso do Solo estadual.

Nesse momento, não havia ainda uma articulação entre ações para a conservação e ações de desenvolvimento para a sociedade local; tratava-se de ações paralelas. As poucas iniciativas de desenvolvimento que lá chegaram estavam relacionadas aos projetos estaduais para desenvolvimento da agricultura familiar e da pesca e obtiveram resultados restritos e ineficientes (Miguel, 1997; Rodrigues, 2002).

A referida instituição estadual, que possuía também a atribuição de órgão de terras, centrava seus esforços no impedimento tanto da ocupação de Guaraqueçaba pelos neolatifundiários, como de ações que beneficiassem a exploração dos recursos naturais (construção de estrada, desmatamento e loteamentos). Estes foram considerados os principais responsáveis pela degradação ambiental em Guaraqueçaba, não somente por suas atividades produtivas diretas (madeira, palmito, búfalo), como também pelos efeitos da grilagem (Teixeira, 2004). Ao expropriar os pequenos agricultores, a ocupação provocava o êxodo rural e o deslocamento da pequena agricultura para terras menos férteis e mais "frágeis", agravando os problemas ambientais e sociais da região (Miguel, 1997). A pequena agricultura não era considerada responsável direta pela degradação, ainda que a legislação fosse, sobre ela, aplicada. Refletindo a postura do governo do estado (1982-1985) de defesa da pequena agricultura familiar e envolvendo-se com a questão fundiária local, os técnicos do órgão ambiental atuantes em Guaraqueçaba conseguiram articular as causas social e ambiental (Teixeira, 2004).

Nos anos de 1990, o órgão ambiental federal (Ibama), em parceria com ONGs, intensificou suas ações em Guaraqueçaba, procurando efetivar a implantação da APA (novo zoneamento, plano de gestão, organização dos grupos de trabalho etc.). Ao mesmo tempo, o órgão ambiental estadual afastava-se da gestão da APA, desligando-se em 2000. 
Reafirmou-se a importância de Guaraqueçaba como área de proteção. Foi criada a Reserva da Biosfera Vale do Ribeira - Serra da Graciosa (1992), que abrangeu todas as unidades de conservação da região. Os conflitos fundiários praticamente cessaram e os neolatifundiários "abandonaram" a região. A legislação ambiental tornou-se mais restritiva a partir do Decreto Mata Atlântica (1991, 1993), acirrando os conflitos entre os pequenos agricultores e as restrições impostas pelos órgãos ambientais. A "ótica ambientalista" predominava sobre a "ótica social", e as propostas de articulação entre conservação e desenvolvimento, calcadas na perspectiva da sustentabilidade alcançaram a pequena agricultura familiar.

Dando continuidade ao período anterior, a partir de 2000 até o ano de $2003,{ }^{6}$ novos elementos passaram a fazer parte da conservação e do desenvolvimento local, acentuando algumas tendências anteriores e introduzindo outras - a reserva particular para seqüestro de carbono, o Pólo de Agroecologia e as novas exigências colocadas pelo SNUC para implantação da APA, dentre elas, a participação da população local na sua gestão.

A sustentabilidade do uso dos recursos naturais: solução técnica para a ocupação bumana

A partir dos anos de 1990, o Ibama passou a receber recursos financeiros do Programa Nacional do Meio Ambiente (PNMA) para executar a implantação de unidades de conservação, incluindo os planos de gestão. Como o Ibama não possuía quadro técnico que pudesse realizar a implantação da APA de Guaraqueçaba, compôs parcerias, seguindo a orientação geral deste órgão. Tais parcerias foram firmadas, sobretudo, com uma ONG ambientalista paranaense, a Sociedade de Pesquisa em Vida Silvestre e Educação Ambiental (SPVS), que ficou responsável pela elaboração de diagnósticos e propostas voltadas à conservação na APA. Ao atrair recursos de ONGs e empresas nacionais e internacionais e ao estruturar um amplo quadro técnico, essa entidade tornou-se, também, o órgão executor das propostas.

Inicialmente, em 1991, a ONG parceira elaborou o Plano de Gerenciamento para a Região de Guaraqueçaba, com recursos da ONG norte- americana The Nature Conservancy (TNC) e apoio do Ibama. Diante da constatação da pobreza local, propôs como solução para os impactos da ocupação humana sobre o meio natural: "desenvolver, aprimorar e implantar modelos de uso sustentado dos recursos naturais disponíveis, de forma a consolidar a conservação e a melhor qualidade de vida da população local" (SPVS, 1995a). Aqui se observa a incorporação das diretrizes internacionais para unidades de conservação, que estabeleciam o uso sustentável como saída para a ocupação humana.

O Plano de Gerenciamento constituiu-se de duas fases: a elaboração do Diagnóstico da Situação Físico-Biológica e Sócio-Econômica da Região e a elaboração do Plano Integrado de Conservação para a Região de Guaraqueçaba, concluído em 1992.

O Diagnóstico partiu do princípio segundo o qual cada região possui uma "vocação" que deve ser pesquisada para a delimitação do potencial regional e posterior aproveitamento racional dos recursos (SPVS, 1992). Concluiu-se que a região de Guaraqueçaba era predisposta a ser uma área de conservação, o que foi reforçado pela criação da Reserva da Biosfera. Essa reserva deveria ser gerenciada com base no "modelo de desenvolvimento conservacionista" (Idem, p. 182), ou seja, "sempre que possível, deveria haver a conservação de sistemas tradicionais de uso da terra, propondo-se assim um tipo de relação harmoniosa entre as populações nativas/tradicionais e o meio natural" (Idem, ibidem).

Contudo, o Plano Integrado afirmava que "a grande maioria das atividades antrópicas desenvolvidas na região eram, senão incompatíveis, conflitantes com os objetivos de conservação de um dos últimos remanescentes da Floresta Atlântica e do complexo estuarino" (Idem, p. 19). Diversamente dos anos de 1980, quando se atribuiu responsabilidade diferenciada aos grupos sociais sobre a degradação ambiental, o Plano Integrado atribuiu a mesma responsabilidade a toda sociedade local. Nesse caso, a pequena agricultura passou a ser, também, uma ameaça àquela "vocação" de Guaraqueçaba. Não havia um grupo social mais ou menos responsável pela degradação ou pela conservação, mas práticas de uso mais ou menos responsáveis pela degradação ou pela conserva- 
ção. Nesse sentido, as ações junto à população deveriam desenvolver a racionalização do uso dos recursos naturais, e a população deveria "receber preparação adequada para esse convívio em novas bases com a natureza" (Idem, p. 12), o que justificou o empenho no desenvolvimento da educação ambiental.

É importante observar que a SPVS é uma ONG voltada à conservação ambiental ${ }^{7}$ que se deparou com a necessidade de considerar a sociedade local como parte deste processo. Os financiadores de seus projetos e seus parceiros exigiam a avaliação dos múltiplos aspectos envolvidos na gestão da conservação, particularmente dos aspectos socioeconômicos e culturais da população local. O Diagnóstico e o Plano de Gestão assim o fizeram. Eles abrangeram em sua pesquisa a história da ocupação de Guaraqueçaba, a pobreza local, a legislação ambiental inadequada e a falta de regularização fundiária, mas, ao trazer a população para o processo de proteção na APA, os aspectos sociais foram diluídos dentro do contexto prioritário da conservação do meio natural. O desenvolvimento socioeconômico, a melhoria da qualidade de vida e a regularização fundiária são mudanças que deveriam ocorrer para o sucesso da conservação, de acordo com as observações relativas à sustentabilidade limitada. No entanto, deixou-se de dar atenção à pobreza e/ou à exclusão social em si, essas questões passaram a ser referidas em função da conservação ambiental. As soluções restringiram-se, dessa forma, à apropriação de técnicas de uso dos recursos naturais.

$\mathrm{Na}$ medida em que as características que definem a especificidade da sociedade não foram consideradas devidamente, submeteu-se o que era singular ao rol de soluções técnicas para a conservação ambiental. Não houve uma concepção construída sobre a inter-relação que se estabelece entre sociedade e natureza, na perspectiva da interdependência e da autonomia desses sistemas. Ou seja, ao não ser considerada em sua especificidade, a sociedade tornou-se "naturalizada".

A partir do Plano Integrado, a SPVS elaborou o Programa Guaraqueçaba, o qual fez parte do convênio estabelecido entre o Ibama e a SPVS em 1994, para a co-gestão da APA de Guaraqueçaba (Convênio 14/94). ${ }^{8}$ Ele foi constituído por projetos distintos que atuavam na pesquisa e na implantação de tecnologias visando à conservação, na articulação institucional para planejamento e execução das ações, além de desenvolver ações comunitárias e de educação ambiental (SPVS, 1995a e b). Tais projetos atendiam, também, aos objetivos estabelecidos nos Planos Operacionais Anuais (POA) do Ibama (educação ambiental, diagnóstico cultural, desenvolvimento comunitário e conservação do estuário).

Outros projetos ainda foram realizados, envolvendo parcerias e recursos de programas nacionais, como o PROBIO, ou internacionais (TNC, Philipp Moris, WWF), em que se previam a organização comunitária para a execução de soluções técnicas, a ostreicultura, a recuperação florestal, a proteção de espécies em extinção, a sistematização de informação, entre outras ações.

Vale dizer que a ação voltada à população mais significativa e aceita pela SPVS era a educação ambiental. Elaborado por biólogos (SPVS, 1995b), o projeto educacional refletia os objetivos definidos desde o início, ou seja, a preparação da população para aceitar as bases de constituição da APA. Em contrapartida, a auto-organização das comunidades era vista com reservas, uma vez que a elaboração da solução técnica, a partir do conhecimento científico, não requeria participação da população, que, assim deveria se adequar às soluções propostas (Teixeira, 2004). No entanto, por exigências contratuais, foram executados projetos relativos a estudos e organização de populações tradicionais localizadas nas ilhas, mas os resultados e as discussões sobre o papel da população local na proteção ambiental se realizaram de maneira não articulada às principais ações de conservação. Em virtude da própria constituição e dos objetivos da ONG em questão, havia dificuldade em aceitar a sociedade (cultura, interesses de grupos sociais) como agente, e não somente como subordinada, da conservação. Essa visão estendia-se ao trabalho de cientistas sociais, e suas propostas no quadro técnico não eram muito aceitas (Idem).

Considerando em particular a pequena agricultura, as ações propostas pelo Plano Integrado envolviam desde a revisão da legislação, especialmente o Decreto Mata Atlântica, até pesquisas sobre os sistemas de produção. O único projeto voltado exclusivamente à pequena agricultura foi $\mathrm{O}$ projeto "Viabilidade Agropecuária", que, posteriro- 
mente, recebeu uma outra denominação: "Difusão de tecnologias na região de Guaraqueçaba". Em relação às práticas agrícolas tradicionais, a posição do Plano Integrado foi taxativa: "o desmatamento e a intensificação do solo, como elementos predominantes dos modelos tradicionais de desenvolvimento são absolutamente rejeitados como formas de atividade econômica" (SPVS, 1992, p. 12). A saída proposta, realizada em convênio com outras ONGs, foi a difusão de alternativas tecnológicas para a produção orgânica e agroflorestal, com o objetivo de melhorar a produtividade da banana e a renda monetária dos agricultores. O projeto foi desenvolvido junto aos agricultores da Associação dos Moradores e Pequenos Produtores Rurais de Batuva, que possuíam melhores condições de produção e comercialização de produtos agrícolas (SPVS, 1995b), além de uma organização comunitária mais estruturada. O principal resultado foi a certificação da banana orgânica.

Estabelecidos os referenciais para pensar ações de conservação para Guaraqueçaba, definidos pela SPVS em parceria com o Ibama, o próximo passo do Ibama foi a elaboração de um Plano de Gestão ${ }^{9}$ para a APA, em conjunto com a Secretaria de Estado do Meio Ambiente (Sema) do Paraná, em 1994. Com a participação de 26 instituições governamentais e não-governamentais, realizou-se uma Oficina de Planejamento de Projetos, na qual se procurou articular o desenvolvimento socioeconômico à conservação através do uso sustentável dos recursos naturais.

No Plano de Gestão foi dada maior atenção às questões sociais do que àquelas presentes no Plano Integrado, o que se justifica pela participação de órgãos estaduais de desenvolvimento e do órgão estadual ambiental. Vale lembrar que o debate em torno da relação entre desenvolvimento e conservação estava fortalecido tanto na esfera nacional como internacional, e na Rio-92 a noção de desenvolvimento sustentável foi oficializada, refletindo-se nas diretrizes para a implantação de unidades de conservação sob a perspectiva de uso sustentável dos recursos naturais.

A idéia de que a pobreza da população local era anterior à proteção ambiental, por ausência de programas de desenvolvimento e pelo isolamento da região de Guaraqueçaba, foi enfaticamente introduzida no Plano de Gestão. A conser- vação foi considerada, pela primeira vez, mais um obstáculo ao desenvolvimento local: "Foi imposta à população e empresários locais [receberam] ao longo dos últimos 10 anos o estigma das precárias condições socioeconômicas às quais a população local [estava] submetida" (Paraná, Sema, 1995, p. 50).

Observa-se, contudo, que esse documento não representou um consenso em torno da conservação em Guaraqueçaba, mas uma sobreposição de interesses das instituições envolvidas. O "objetivo superior" do Plano de Gestão era "conservar a diversidade de ambientes, de espécies, de processos naturais e do patrimônio cultural, visando o desenvolvimento econômico ambientalmente sustentado das comunidades humanas locais e a melhoria da qualidade de vida" (Idem, p. 59). O "objetivo da gestão" retoma sutilmente o sentimento de justiça social dos anos de 1980: a "gestão ambiental integrada" deveria estimular "atividades econômicas ambientalmente sustentáveis e socialmente justas" (Idem, ibidem). Para isso, propôs um Programa de Desenvolvimento Sustentável, seguindo as diretrizes internacionais e nacionais sobre o tema.

Esta foi a primeira vez que um programa para Guaraqueçaba utilizou a noção de desenvolvimento sustentável que não se restringia ao uso sustentável, mas incluía dimensões como a sustentabilidade econômica e social e a participação social, como consta na Agenda 21 Global.

O Programa de Desenvolvimento Sustentável previa regularização fundiária, modificações e complementações na legislação, estímulo aos nichos de mercado (selo, atestado verde, indústria caseira), práticas de manejo agrícola integradas, linha de crédito para os pequenos produtores e incentivo à pesquisa para o desenvolvimento de tecnologias compatíveis com a proteção. De certa forma, a pequena agricultura não foi tratada como uma prática incompatível, mas como uma atividade produtiva que requeria condições estruturais para o seu desenvolvimento, ainda que subordinado à conservação.

O sentido de desenvolvimento pode ser observado também na proposição do ecoturismo e nas demais propostas para a viabilização de alternativas de trabalho, a manutenção da população tradicional, a qualificação de serviços sociais e in- 
fra-estrutura, para as quais se poderiam usar os recursos advindos do ICMS ecológico.

Contudo, o Plano de Gestão, incluindo o Programa de Desenvolvimento Sustentável, não foi executado por falta de recursos humanos e financeiros das instituições que deveriam arcar com a sua execução, inclusive dos órgãos estaduais voltados ao desenvolvimento. Assim, as ações de desenvolvimento permanecem até hoje restritas ao Ibama/SPVS.

A única ação prevista e realizada pelo Plano de Gestão foi o Zoneamento da APA de Guaraqueçaba, a cargo do Instituto de Pesquisa e Desenvolvimento do Paraná (Ipardes), no período de 1994 a 1997, com recursos do Ibama. Demonstrando maior atenção à sociedade local, o zoneamento possui um capítulo sobre a população tradicional local elaborado a partir de dois estudos anteriormente realizados para o projeto de Cogestão Ibama/SPVS. Seu resultado foi considerado por essas instituições, muito amplo e pouco diretivo, uma vez que não definia os usos possíveis das diferentes "zonas" da APA (Teixeira, 2004). Publicado em 2001, o zoneamento não foi ainda normatizado.

Para substituir o Plano de Gestão de 1995, em 1999 o governo do Paraná e o Ibama, em parceria com a SPVS, elaboraram o programa Guaraqueçaba pra frente, Guaraqueçaba sempre: programa de desenvolvimento sustentável para a Área de Proteção Ambiental de Guaraqueçaba. Retirando as referências à justiça social, este programa redefiniu os papéis das instituições atuantes, cabendo ao Ibama/SPVS o controle da gestão e das pesquisas e a produção de técnicas adaptadas aos objetivos da conservação (Paraná/Sema/IAP, 1999). Este programa também não foi ainda executado.

Dado o fracasso dessas duas propostas de ação conjunta (órgãos ambientais e de desenvolvimento), não houve distribuição de funções entre os órgãos ambientais e demais instituições voltadas ao desenvolvimento socioeconômico da região. Paralelamente, as raras iniciativas de desenvolvimento da pequena agricultura por parte do governo do estado que chegaram a Guaraqueçaba obtiveram resultados pífios (Rodrigues, 2002).

A distribuição de funções e as ações articuladas não garantiriam, por si só, uma outra pers- pectiva que não a da "naturalização" da sociedade; as condições para a sua superação residiriam para além da idéia de uso sustentável dos recursos naturais.

Restritas aos agentes da conservação, as ações que foram desenvolvidas junto à pequena agricultura se mantiveram na esfera das soluções técnicas para a produção, ainda que fizessem referência ao aumento da renda e da qualidade de vida dos agricultores envolvidos. Não houve uma articulação efetiva com análises antropológicas ou sociológicas sobre sociedade local, o que levou a um segundo plano a preocupação com os efeitos (ambientais e sociais) perversos da conservação, os quais variam de práticas clandestinas de uso dos recursos naturais ao aumento da situação de pobreza de alguns agricultores. Como exemplo, a pesquisa realizada por Francisco (2002) descreve as conseqüências da introdução da produção de banana orgânica para nichos de mercado sobre uma comunidade de Guaraqueçaba. Romperamse laços e práticas de sociabilidade que garantiam a sobrevivência daqueles agricultores, cujas condições de produção foram consideradas insuficientes para a inclusão na produção orgânica.

A partir de 2000, novos elementos foram introduzidos na condução da gestão da APA de Guaraqueçaba e, definitivamente, o desenvolvimento sustentável passou a ser considerado a solução para a ocupação humana nessa unidade de conservação. Reiterando, isso ocorreu sob a perspectiva da "naturalização" da sociedade.

No mesmo ano, independentemente do Ibama, a SPVS adquiriu propriedades em Guaraqueçaba, formando uma reserva particular para o desenvolvimento do projeto de seqüestro de carbono. Ao lado das ações de controle, o plano de ação elaborado pelas ONGs TNC e SPVS exigia que esta última se responsabilizasse por programas de desenvolvimento sustentável visando à integração das comunidades do entorno das reservas ao projeto de seqüestro de carbono, além da eliminação das atividades produtivas e extrativas incompatíveis com os objetivos do projeto (TNC/SPVS, 2000).

A SPVS não desenvolveu projeto próprio de desenvolvimento sustentável, mas incrementou as ações do Pólo de Agroecologia do Litoral do Paraná, desenvolvido pela Emater e pela Secretaria de 
Estado de Agricultura e Abastecimento, em parceria com ONGs e outros segmentos da sociedade, a partir de 2000. Seus principais objetivos são: "viabilizar a agricultura familiar através do desenvolvimento de tecnologias adaptadas para a região, buscando a integração das atividades agrícolas, conservação do meio ambiente e desenvolvimento social" (Emater, 2003). Observa-se que nesse projeto a agricultura familiar, e portanto a sociedade, aparece em primeiro plano se comparada às idéias de conservação ambiental.

Considera-se que a SPVS impulsionou as ações do Pólo, com recursos captados por ela mesma (Bona, 2003 apud Chang, 2004) e introduziu a técnica do Diagnóstico Rural Participativo (DRP), cujo objetivo é "saber como essas pessoas se relacionam com a floresta e somar ao nosso conhecimento técnico-científico, já que é mais fácil os agricultores adotarem técnicas que estejam próximas à sua realidade" (O Estado de S. Paulo, 2002). Em uma comunidade agrícola, a SPVS propôs associar a banana ao manejo comunitário do palmito, como já havia sido sugerido por estudos não vinculados ao Ibama/SPVS no início dos anos de 1990 (Miguel e Zanoni, 1998). Segundo Chang (2004), a SPVS estaria redefinindo a sua identidade institucional ao incluir tais dimensões em suas ações conservacionistas. Esta redefinição pode ser explicada a partir da necessidade de adequação das ações às exigências de seus parceiros e à sociedade local (Teixeira, 2004). Sob o ângulo da "naturalização" da sociedade evidenciou-se, por exemplo, que o sucesso do "desenvolvimento local" e da conservação depende de condições materiais e organizacionais de produção, o que a maior parte da pequena agricultura em Guaraqueçaba não possui, como mostram os estudos de Miguel (1997) e Rodrigues (2002).

Em 2002, as determinações do SNUC começaram a ser implementadas na APA de Guaraqueçaba, dentre elas, aquelas cuja orientação era a promoção do desenvolvimento sustentável. A grande transformação ficou por conta da criação do Conselho Deliberativo que vem sendo realizado pelo Ibama/SPVS. Esse conselho inclui os representantes das comunidades por bacias hidrográficas, as instituições presentes na APA, assim como ONGs e universidades (Idem).
A partir das novas propostas e dos programas implantados em Guaraqueçaba nos últimos anos, e a partir das experiências realizadas anteriormente com a pequena agricultura, a noção de desenvolvimento sustentável foi definitivamente apropriada pelos agentes responsáveis pela gestão da APA. O desenvolvimento sustentável aqui empregado é o mesmo legitimado na Rio-92, e se enquadra na perspectiva da sustentabilidade limitada ou sustentabilidade ponte (Foladori e Tommasino, 2000), ponte para a conservação ambiental e ponte para assegurar o sucesso do projeto de seqüestro de carbono. Tanto este projeto como o próprio SNUC, ao incorporarem o desenvolvimento sustentável, extrapolando a idéia de uso sustentável, proporcionaram uma nova situação à gestão da APA (Teixeira, 2004), ainda que não problematizassem a noção de desenvolvimento sustentável.

Na APA de Guaraqueçaba, os novos rumos podem modificar a relação entre a conservação e a sociedade local, situando a população como um elemento não só a ser controlado, mas também a ser reconhecido e considerado em sua especificidade e na sua inter-relação com o ambiente, além de ter garantidos seus direitos de decisão sobre o futuro. Contudo, essa mudança ainda está subjugada à "vocação" de Guaraqueçaba, para a qual a população deve ser preparada. O que surgirá com a participação da sociedade local neste processo, está em construção.

\section{Considerações finais}

Para alcançar a conservação ambiental na APA de Guaraqueçaba, além do controle da fiscalização e do licenciamento, a solução encontrada para a pequena agricultura local, por suas instâncias co-gestoras, partiu da perspectiva da "naturalização" da sociedade e se restringiu à implantação de técnicas produtivas adequadas aos objetivos da conservação. Assim, os problemas decorrentes das práticas de uso dos recursos naturais da população local sobre a conservação foram reduzidos aos efeitos negativos das primeiras sobre a segunda.

Diante de diretrizes internacionais no contexto do debate sobre a sustentabilidade e seguindo princípios conservacionistas e exigências im- 
postas por parcerias e financiamentos, o desenvolvimento sustentável foi apresentado como objetivo para a APA de Guaraqueçaba, ainda que subordinado à sua "vocação" de conservação da APA. Além das exigências contratuais, as reações da própria população à conservação e aos projetos de uso sustentável ou de geração de renda indicavam que uma nova postura seria necessária para lidar com a ocupação humana nesta unidade de conservação, abrindo outras perspectivas para realizar o desenvolvimento local.

A pequena agricultura em Guaraqueçaba não alterou estruturalmente sua precária condição de reprodução e, conseqüentemente, não alterou práticas consideradas contrárias aos objetivos da conservação. Os poucos resultados positivos de programas de desenvolvimento para a pequena agricultura foram localizados e restritos. Mas isto vem se expandindo com as ações do Pólo de Agroecologia, nas quais os órgãos de desenvolvimento do estado estão presentes de forma mais efetiva e articulada à conservação.

A visibilidade da conservação é o meio natural. A ocupação humana é considerada um problema e não parte - inter-relacionada - da proteção ambiental. As questões mais estruturais, que efetivamente constroem uma visão da sociedade local - a partir de características que definem uma sociedade e, conseqüentemente, suas relações com o meio natural - e não somente da população local, ainda não são fundamentais nos projetos que pretendem alterar técnicas de uso dos recursos naturais.

Identificar a "naturalização" do social como característica do desenvolvimento sustentável na APA de Guaraqueçaba, o que talvez possa ser extrapolado para outras unidades de conservação, contribuiu para a reflexão sobre a relação entre desenvolvimento econômico e conservação ambiental e sobre desenvolvimento sustentável como solução para ocupação humana em unidades de conservação, o que implica, em última instância, refletir sobre a inter-relação entre a sociedade e seu ambiente. Além disso, e relacionado a esses fatores, podemos pensar o papel do profissional das ciências sociais nas discussões e nas ações de desenvolvimento articuladas à conservação ambiental.

Para esses profissionais interessa saber quais as conseqüências de projetos de desenvolvimento sustentável fundamentados na "naturalização" da sociedade. Ao propor soluções técnicas, deve-se observar primeiramente se a sociedade que recebe as propostas é considerada como tal. A implantação de novas técnicas para produção ou de programas de geração de renda muitas vezes encontraram seus limites quando efetivamente executados, uma vez que as condições sociais foram secundarizadas ou negligenciadas nas soluções propostas.

Ademais, os efeitos das transformações nas técnicas de produção sobre a sociedade geralmente não são levados em consideração, inclusive em se tratando de sustentabilidade social, pré-requisito para o pretendido desenvolvimento sustentável. O caso da agricultura orgânica em ecossistemas como o encontrado em Guaraqueçaba, por exemplo, suscitam questões como: Qual o acréscimo de força de trabalho é necessário para produzir arroz orgânico? Quantas faltas na escola serão necessárias para que o filho do agricultor possa retirar com as mãos as ervas daninhas da cultura do arroz? Que mudanças ocorrem nas relações sociais de uma comunidade com a introdução de técnicas de produção que dispensam o mutirão? Enfim, qual o custo social das ações propostas em nome da sustentabilidade ecológica?

Se considerarmos a abordagem interdisciplinar do meio ambiente, caberia às ciências sociais a responsabilidade de pensar essas questões, ajudando inclusive em programas e propostas de desenvolvimento sustentável em unidades de conservação. De certa forma, deve-se resistir à sedução e conseqüente apropriação de conceitos e modelos de sustentabilidade oriundos de outras áreas de conhecimento mais vinculadas à conservação. Os modelos devem ser enfrentados na construção interdisciplinar do conhecimento, e as ciências sociais devem manter a "identidade" do conceito de sociedade. Assim, o desenvolvimento pode sair da esfera técnica, ou seja, da procura de melhores técnicas adaptadas à conservação, para um debate mais amplo que envolve, em última instância, a discussão sempre recorrente sobre a relação sociedade e natureza.

\section{Notas}

1 No zoneamento, a área protegida é dividida em zonas, de acordo com critérios "ambientais", para as 
quais são definidas as formas de ocupação humana possíveis.

2 A Agenda 21 Global é um programa de ação que define diretrizes para o desenvolvimento "conciliando métodos de proteção ambiental, justiça social e eficiência econômica" (http://www.agenda 21.org.br/intro.htm).

3 As Unidades de Proteção Integral- Estação Ecológica e Parque Nacional - admitem apenas o uso indireto dos recursos naturais, como pesquisa e educação ambiental (Lei n ${ }^{\circ} 9.985 / 2000$, Art. $7^{\circ} \S 1^{\circ}$ ).

4 Além dessa Área de Proteção Ambiental, a região possui um Parque Nacional, uma Estação Ecológica e duas Reservas Particulares do Patrimônio Natural (RPPN).

5 Atualmente, mesmo os ganhos elevados de arrecadação graças ao recebimento do ICMS ecológico, o município possui um dos dez piores IDH - Índice de Desenvolvimento Humano do estado do Paraná.

6 Ano em que terminou o levantamento de dados que subsidiou a elaboração deste artigo.

7 Formada inicialmente por zoólogos e um veterinário, seu nome define seus objetivos iniciais (pesquisa em vida silvestre), o que, posteriormente, se expande para a pesquisa e as soluções técnicas para a conservação ambiental.

8 Além dos recursos do PNMA e da FNMA - Fundo Nacional do Meio Ambiente, esses projetos constaram com um pool de financiadores: O Boticário, Unibanco, MacArthur Foundation, e USDA Forest Service.

9 Elaborar um plano de gestão com a participação das demais instituições envolvidas na unidade de conservação (prefeitura, secretarias de estado etc.) é uma exigência a ser cumprida para implantação da APA.

\section{BIBLIOGRAFIA}

BRITO, M. C. W. (2000), Unidades de conservação: intenções e resultados. São Paulo, Anablume/Fapesp.

BECKER, D. F. (1999), "Sustentabilidade: um novo (velho) paradigma de desenvolvimento regional", in D. F. Becker (org.), Desenvolvimento sustentável: necessidade ou possibilidade, 2 ed., Santa Cruz do Sul, Edunisc.

CASTELLS, M. (2000), A era da informação: economia, sociedade e cultura (vol. 2: O poder da identidade). São Paulo, Paz e Terra.

CHANG, M. (2004), Seqüestro de carbono florestal no Brasil: dimensões politicas, socioeconômicas e ambientais. Tese de doutorado em Meio Ambiente e Desenvolvimento da Universidade Federal do Paraná, Curitiba.

DIEGUES, A. C. (1998), O mito da natureza intocada. 2 ed. São Paulo, Hucitec.

. (2000), "Etnoconservação da natureza: enfoques alternativos", in (org.), Etnoconservação: novos rumos para a proteção da natureza nos trópicos. São Paulo/Hucitec/NUPAUB-USP.

EMATER - Agricultura orgânica/agroecológica. (2003), "Seminário interno de troca de experiências". Disponível em http://www.emater.or.gov/agrorg/Seminar/Pg35.html (acesso em 20 dez.).

FRANCISCO, E. C. (2003), Agricultura familiar em área de proteção ambiental: estratégias de reprodução de um modo de vida. Dissertação de mestrado. Curitiba, Universidade Federal do Paraná.

FOlADORI, G. (1999), Los límites del desarrollo sustentable. Montevidéu, Ediciones de la Banda Oriental - Revista Trabajo e Capital.

FOLADORI, G. \& TOMMASINO, H. (2000), "El concepto de desarollo sustentable treinta años después". Desenvolvimento $e$ Meio Ambiente, 1, Curitiba, Editora da UFPR.

FUNDAÇÃO SOS PRÓ-MATA ATLÂNTICA. (1986), Dossiê complexo estuarino lagunar de Iguape, Cananéia e Paranaguá de 1986. São Paulo, s. e. 
IPARDES - Instituto Paranaense de Desenvolvimento Econômico e Social. (2001), Zoneamento da APA de Guaraqueçaba. Curitiba, Ipardes.

LEFF, E. (2000), Ecologia, capital e cultura: racionalidade ambiental, democracia participativa e desenvolvimento sustentável. Blumenau, Edifurb.

LEIS, H. R. (1999), A modernidade insustentável: as críticas do ambientalismo à sociedade contemporânea. Petrópolis/Florianópolis, Vozes/Editora da UFSC.

LEIS, H. R. \& VIOLA, E. (1996), "A emergência e evolução do ambientalismo no Brasil", in H. R. Leis, O labirinto: ensaios sobre ambientalismo e globalização, São Paulo/Blumenau, Gaia/Fundação Universidade de Blumenau.

LÉLÉ, S. M. (1991), "Sustainable development: a critical review". World Development, 19 (6): 607-621, jun.

MIDDLETON, N. \& O’KEEFE, P. (2001), Redefining sustainable development. Londres/Sterling, Pluto Press.

MIGUEL, L. de A. (1997), Formation, evolution et transformation d'un système agraire dans le sud du Brésil (Litoral Nord de l'état du Paraná). Une paysannerie face à une politique de protection de l'environnment: "Cronique d'une mort annoncée?". Tese de doutorado, Institut National Agronomique, Paris/Grignon.

MIGUEL, L. \& ZANONI, M. (1998), "Práticas agroflorestais - políticas públicas e meio ambiente: o caso do litoral do estado do Paraná. Extensão Rural, ano 5, jan.-dez., Santa Maria, DEAR/CPGExR-CCR-UFSM.

MIRANDA, R. B. (2003), "As relações sociedade/natureza sob a perspectiva da co-evolução". Desenvolvimento e Meio Ambiente, 8, jul.-dez., Curitiba, Editora da UFPR.

NOBRE, M. (2002), "Desenvolvimento sustentável: origens e significado atual", in NOBRE, M. Nobre e M. C. Amazonas (orgs.), Desenvolvimento sustentável: a institucionalização de um conceito, Brasília, Ibama.

O ESTADO DE S. PAULO. (2002), 13 set. Disponível em http://www.estadao.com.br/ ciencia/noticias/2002/set/13/88.htm (acesso em 20 abril de 2003).

PARANÁ - Governo do Estado do Paraná; SEMA Secretaria de Estado do Meio Ambiente \& IAP - Instituto Ambiental do Paraná. (1999), Programa de desenvolvimento sustentável da área de proteção ambiental de Guaraqueçaba. Curitiba, IAP.

. (1995), Plano de gestão ambiental de Guaraqueçaba: área de proteção ambiental de Guaraqueçaba. Curitiba, IAP.

RAYNAUT, C. (1994), "O desenvolvimento e as lógicas de mudança: a necessidade de uma abordagem holística". Cadernos de Desenvolvimento e Meio Ambiente, 1, Curitiba/Bordeaux, Editora da UFPR/GRID.

. (1997), Les Sahels: diversité et dynamiques des relations sociétés-natures. Paris, Kartjal.

RAYNAUT, C.; LANA, P. \& ZANONI, M. (2000), "Pesquisa e formação na área de meio ambiente e desenvolvimento: novos quadros de pensamento, novas formas de avaliação". Desenvolvimento e Meio Ambiente, 1, jul.-dez., Curitiba, Editora da UFPR.

RODRIGUES, A. (2002), A sustentabilidade da agricultura em Guaraqueçaba: o caso da produção vegetal. Tese de doutorado em Meio Ambiente e Desenvolvimento da Universidade Federal do Paraná, Curitiba.

SPVS - Sociedade de Pesquisa em Vida Selvagem e Educação Ambiental. (1995a), "Relatório anual 1994", in SPVS, Programa Guaraqueçaba, Curitiba, mar.

(1995b), "Informe técnico: de 1 de janeiro a 31 de agosto de 1995", in SPVS, Programa Floresta Atlântica Guaraqueçaba, Curitiba, out. 
SPVS - Sociedade de Pesquisa em Vida Selvagem e educação Ambiental \& TNC - The Nature Conservancy. (1992), "Relatório anual", in SPVS, Plano integrado de conservação para a região de Guaraqueçaba. Curitiba.

TEIXEIRA, C. (20004), A proteção ambiental em Guaraqueçaba: uma construção social. Tese de doutorado em Meio Ambiente e Desenvolvimento da Universidade Federal do Paraná, Curitiba.

TNC - The Nature Conservancy \& SPVS - Sociedade de Pesquisa em Vida Silvestre e Educação Ambiental. (2000), Central and South West Corporation - Guaraqueçaba Climate Action Project. Project Plan. Curitiba, mar.

TOMMASINO, H. (2002), Insustentabilidad o sustentabilidad "puente"? Análisis de La Producción Animal en el Municipio (APA) de Guaraqueçaba, Paraná, Br. Curitiba. Tese de doutorado em Meio Ambiente e Desenvolvimento da Universidade Federal do Paraná, Curitiba.

VARGAS, P. R. (1999), "O insustentável discurso da sustentabilidade" in D. F. Becker (org.), Desenvolvimento sustentável: necessidade ou possibilidade, 2 ed., Santa Cruz do Sul, Edunisc.

ZANONI, M. \& RAYNAUT, C. (1994), "Meio ambiente e desenvolvimento: imperativos para a pesquisa e a formação. Reflexões em torno do doutorado da UFPR". Desenvolvimento e Meio Ambiente, 1, Curitiba/Bordeaux, Editora da UFPR/GRID. 


\section{O DESENVOLVIMENTO SUS- TENTÁVEL EM UNIDADE DE CONSERVAÇÃO: A "NATURA- LIZAÇÃO” DO SOCIAL}

Cristina Teixeira

\section{Palavras-chave}

Desenvolvimento sustentável;

Sociedade e ambiente; Unidade de conservação.

A noção de desenvolvimento sustentável é utilizada por órgãos governamentais e organizações não-governamentais (ONGs) para solucionar problemas relativos à ocupação humana em unidades de conservação. Nesses espaços, os problemas relativos à articulação entre desenvolvimento e conservação podem ser observados, levando à reflexão sobre a pertinência da própria noção de desenvolvimento sustentável. Este artigo analisa as propostas de desenvolvimento - aliadas à conservação - para a Área de Proteção Ambiental de Guaraqueçaba, localizada no litoral norte do Paraná, identificando alguns elementos que interessam particularmente ao cientista social. Entre eles, a "naturalização" da sociedade presente na proposição de soluções para os "impactos" ambientais causados pela pequena agricultura local.

\section{SUSTAINABLE DEVELOPMENT IN CONSERVATION UNITS: NATURAZATION OF THE SOCIETY}

Cristina Teixeira

\section{Key-words}

Sustainable development; Society and environment; Conservation units.

The notion of sustainable development is employed by governmental and Non-Governmental Organizations (NGOs) to solve problems related to human occupation in conservation units. In these areas there are problems between development and conservation. It arouses debates around the notion of sustainable development. This paper analyses the development proposals - which includes conservation - to the Environmental Protection Area of Guaraqueçaba, located in the north of the state of Paraná, working on some elements that concern social scientists. Among these elements, we take notice that in the proposals to solve environmental problems caused by local agriculture, there is a process of naturalization of the society.

\section{LE DÉVELOPPEMENT DURA- BLE DANS LES ZONES PROTÉ- GÉES: LA "NATURALISATION" DE LA SOCIÉTÉ}

\author{
Cristina Teixeira
}

\section{Mots-clés}

Développement durable; Société et environnement, Zones protégées.

La notion de développement durable est utilisée par des organismes gouvernementaux et des organisations non gouvernementales pour résoudre des problèmes liés à l'occupation humaine dans les zones protégées. Dans ces espaces, les problèmes relatifs à l'articulation entre le développement et la conservation peuvent être observés par l'examen de la pertinence de la notion de développement durable. Cet article analyse les propositions de développement alliées à la conservation dans le cadre de l'Aire de Protection Environnementale (APA) de Guaraqueçaba, située sur la côte Nord de l'État de Paraná (Brésil). Il identifie quelques éléments qui intéressent particulièrement les spécialistes en sciences sociales, parmi lesquels la "naturalisation" de la société, présente dans la proposition de solutions pour les impacts environnementaux causés par l'agriculture locale. 